\title{
O APARATO DE SEGURANÇA PÚBLICA: ENTRE A CONSTITUIÇÃO E A “ORDEM"
}

\section{THE APPARATUS OF PUBLIC SAFETY: BETWEEN THE CONSTITUTION AND THE "ORDER"}

\author{
Diego Nogueira ${ }^{1}$
}

\begin{abstract}
RESUMO
Este artigo tem como objetivo discutir criticamente o sistema de segurança pública brasileira, e abrange especialmente a necessidade de fortalecimento de sistemas de comunicação que aprimorem e democratizem a polícia militar como instituição. Reservas e forças auxiliares do Exército, as polícias militares são apresentadas como verdadeiras quimeras (são forças militares, mas trabalham com uma atividade civil) e, portanto, têm dificuldade em adaptar-se ao mundo democrático. As reflexões apresentadas são conduzidas pela teoria neoinstitucionalista, e visam à compreensão das dificuldades que devem ser enfrentadas na tentativa de modernização dessas instituições e na resposta às aspirações sociais. A investigação se pauta pelo método dedutivo, subsidiado por pesquisa bibliográfica e documental, e analisa a contraposição entre o discurso constitucional da matéria atinente à segurança pública e a prática, esta ainda fundada em elementos típicos do sistema ditatorial.
\end{abstract}

Palavras-chave: Ordem pública. Polícias militares. Políticas públicas de segurança. Desmilitarização.

\begin{abstract}
This article intend to critically discuss the Brazilian public security system, especially including the need to strengthen communication systems that can improve and democratize the military police* as an institution. The forces of Brazilian Army and the military police are presented as true chimeras (they are military forces, but are working with civilians), and thus have difficulty in adapting themselves to a democratic world. The text is conducted by the neo-institutional theory, and tries to understand the difficulties that must be faced in trying to modernize these institutions and its relation with social aspirations. The research is guided by a deductive method, supported by literature and documents about the subject, and analyzes the contrast between the constitutional discourse related to the public safety and it practice, which is still founded on elements typical of the dictatorial system.
\end{abstract}

Keywords: Public policy. Military police. Public security policies. Demilitarization.

1 Mestre em Políticas Públicas pela UFPR. Oficial da Polícia Militar do Paraná. Professor na Escola Superior de Segurança Pública. E-mail: diegonogueira@ufpr.br. ${ }^{*}$ Brazilian police is divided in different types and functions. What we call in this article "military police" relates to the policemen who work on the streets, acting directly on citizen's daily life. This institution has its roots in the times of the country's dictatorship (1964-1985). 


\section{INTRODUÇÃO}

O tema da violência, embora seja recente para as ciências sociais brasileiras, já acumulou um apreciável acervo de informações, resultados de pesquisas, perspectivas teórico-metodológicas e, inclusive, acirradas polêmicas e debates.

Trata-se de um problema social que, por um lado, promove ampla mobilização da opinião pública, que se pode observar por meio das sondagens de opinião, da insistente atenção que lhe é conferida pela mídia impressa e eletrônica, e pela multiplicação de fóruns locais, regionais e nacionais; por outro lado, vem promovendo impacto sobre o sistema de justiça criminal, influenciando a formulação e implementação de políticas públicas de segurança e justiça (também chamadas de políticas públicas penais) ${ }^{2}$.

Neste domínio, o sistema vem se mostrando completamente ineficaz na contenção da violência no contexto do estado democrático de direito. Problemas relacionados à lei e à ordem têm afetado a crença dos cidadãos nas instituições públicas de segurança.

Os fatos da violência têm tido forte impacto no meio acadêmico. Para além de uma mera preocupação com a fenomenologia da violência - algo talvez mais afinado com uma perspectiva que se poderia identificar como própria da tradição criminológica -, a pesquisa brasileira identificou neste campo um lugar para decifrar, em parte, os rumos contemporâneos desta sociedade ${ }^{3}$.

As bases do sistema público de segurança estão assentadas numa estrutura social historicamente conivente com a violência privada, a desigualdade social, econômica e jurídica e os déficits de democracia de grande parte da população. As instituições encarregadas da vigilância e aplicação da lei não se prepararam para o recrudescimento da criminalidade de forma técnica, agindo quase que exclusivamente de modo reativo.

A aplicação da força policial nas diversas manifestações ocorridas no país em 2013, que reivindicavam melhorias em diversos setores contemporâneos, demonstra a vulnerabilidade destas instituições

2 ADORNO, Sérgio. O monopólio estatal da violência na sociedade brasileira contemporânea [online]. Disponível em: <http://www.nevusp.org/ downloads/down078.pdf>. Acesso em: 06 de jun. 2013.

3 Idem. no trato democrático. A aplicação do excesso pelas tropas de choque no início dos protestos, e a total inércia após a crítica da imprensa contra sujeitos que depredam o patrimônio público, evidenciam a falta de preparo da polícia ${ }^{4}$.

A proposta do presente trabalho é discutir, a partir de uma análise crítica, o sistema de segurança pública brasileira, especialmente a necessidade de fortalecimento de sistemas de comunicação que aprimorem e democratizem a polícia militar como instituição.

Guiada pelo método dedutivo, a investigação é subsidiada por pesquisa bibliográfica e documental, analisando a dicotomia existente entre o discurso constitucional referente à segurança pública e sua prática, fundada no sistema ditatorial

A herança político-institucional e cultural do período ditatorial (1964-1985), geradora de exclusão e afastamento de grandes parcelas da população aos direitos básicos, acentuou o esfacelamento de uma cultura democrática em construção ao enfatizar o controle do Estado em relação às chamadas "classes perigosas".

Neste período da história nacional, o principal objetivo do governo, em correspondência ao autoritarismo político, era eliminar qualquer tendência de discussão de cunho político no âmbito das instituições públicas e da sociedade. Os órgãos de segurança pública não só deveriam se manter como um mecanismo alheio à discussão dessa natureza, como também tinham a atribuição de garantir o distanciamento político das demais políticas públicas e da sociedade como um todo 5 .

\footnotetext{
4 O uso da força como instrumento principal para controlar manifestações públicas e motins, em detrimento de outras técnicas, como negociação, isolamento e dispersão de multidões, também é uma das formas de violência policial. Dado o caráter eminentemente político deste tipo de atividade policial, o controle violento de manifestações públicas como passeatas, greves e protestos é uma das formas mais visíveis de violência policial. Regimes autoritários são facilmente relacionados a esse tipo de violência em função do sistemático uso das polícias para conter a contestação pública. Entretanto, esse tipo de violência policial pode ser encontrado em regimes democráticos; por exemplo, nos EUA, durante as décadas de 1960 e 1970, a polícia era acusada de recorrer frequentemente à violência para conter as manifestações públicas. (In: COSTA, Arthur Trindade Maranhão. Entre a lei e a ordem: violência e reforma nas polícias do Rio de Janeiro e Nova York. Rio de Janeiro: Editora FGV, 2004, p.16.)

5 DIAS, Lúcia Lemos. A Política de Segurança Pública entre o monopólio legitimo da força e os direitos humanos: a experiência da Paraíba no pós 1988. Tese (Doutorado), Universidade Federal de Pernambuco, Programa de Pós-graduação em Serviço Social. João Pessoa, 2010.
} 
Em boa medida, o conceito da doutrina de segurança criado durante este período da história continuou vigorando na estrutura de nossos sistemas estadual e federal de segurança. Até meados da década de 1990, o modelo e as ações de segurança pública limitavam-se à contenção social, a partir do preceito de que "lei e ordem" públicas derivariam do uso da força, das armas e das ações policiais pela exclusiva via da repressão ${ }^{6}$.

Um olhar sobre a história da polícia revela uma faceta da organização das políticas públicas e do gerenciamento do espaço público no Brasil. A questão da segurança e o discurso armamentista que o Estado prega hoje em dia nada mais é que uma artimanha para o controle da massa. Uma vez que a prevenção ao crime é secundária, investe-se no confronto "armado" contra os marginais; mantém-se a população amedrontada, quer por parte da força policial, quer por parte dos bandidos, também armados?

Conjugando práticas clientelistas e patrimonialistas, - que remontam à formação social e à política nacional - nasce um sistema público de segurança a serviço de determinadas classes sociais, legitimadas pelo ordenamento. Tal situação perdura mesmo depois da promulgação da Constituição de 1998, com pequenas investidas democráticas ${ }^{8}$.

Não há como questionar os avanços democráticos após a ditadura de 1964, muito menos a estabilidade das instituições que fazem parte deste regime que é, pelo menos formalmente, democrático. Por outro lado, seria um erro considerar que: (1) a democracia atinge igualmente a todas as classes e grupos sociais, e (2) a ideologia contida no art. 144 da Constituição não seja claramente antidemocrática, inclusive, entrando em conflito com outros artigos do mesmo documento 9 .

Importante esclarecer que as pretensas mudanças institucionais das forças militares estaduais serão analisadas no presente estudo pela vertente teórica do neoinstitucionalismo. Corrente que surgiu como

6 SOUZA, Robson Sávio Reis. Política de segurança: grandes desafios [online]. Disponível em: <http://www.cartacapital.com.br/sociedade/politica-de-seguranca-publica-grandes-desafios>. Acesso em: 02 jun. 2013.

7 PEDROSO, Regina Célia. Estado autoritário e ideologia policial. São Paulo: Fapesp, 2005, p. 49.

8 Idem.

9 MORAES, Pedro Rodolfo Bodê de. Em defesa do Estado ou da sociedade [online]. Disponível em <http://www.ninc.com.br/coluna-especial-detail.php?id_coluna=13>. Acesso em: 27 ago. 2013. síntese epistemológica e metodológica, partindo do antigo institucionalismo, tem como principal marca a volta das instituições ao centro da investigação política, mas com a incorporação de métodos mais rigorosos de análise, bem como com atenção ao comportamento dos indivíduos ${ }^{10}$.

Em especial o neoinstitucionalismo sociológico apresenta contribuições ao presente estudo ao concluir que os procedimentos, regras e normas característicos das instituições modernas não são simplesmente um modo de ação mais eficiente em relação à funcionalidade delas, mas práticas culturais equivalentes aos rituais e cerimônias peculiares de várias sociedades ${ }^{11}$.

As instituições têm, para este enfoque da corrente, um significado muito mais amplo, compreendendo "os sistemas de símbolos, os esquemas cognitivos e os modelos morais que fornecem 'padrões de significação' que guiam a ação humana". A consequência conceitual dessa interpretação é que a oposição entre "instituições" e "cultura" desaparece. No seu lugar, as instituições passariam a corresponder à própria cultura ${ }^{12}$.

Mark Granovetter, embora critique a noção funcionalista da visão neoinstitucionalista, contribui para explicar a manutenção das instituições. Para o autor “(...) as instituições são conjuntos mais complexos de ações individuais que remetem frequentemente à ideia de que é assim que as coisas devem ser feitas"13.

As instituições existentes estão longe de serem as mais eficientes, devendo sua emergência a um êxito no quadro da luta entre várias opções ${ }^{14}$. Afasta-se o argumento darwinista implícito de que "[...] as soluções eficientes, qualquer que seja sua origem, têm uma capacidade para se impor, semelhante àquela gerada pela seleção natural no mundo biológico"15.

As instituições são "contribuições sociais". A forma assumida por estas é fortemente condicionada pelo conteúdo e pela estrutura das relações

\footnotetext{
10 PERES, Paulo Sérgio. Comportamento ou instituições? A evolução histórica do neoinstitucionalismo da ciência política. Revista Brasileira de Ciências Sociais [online]. São Paulo, vol. 23, n. 68, 2008.

11 HALL, Peter A.; TAYLOR, Rosemary C. R. As três versões do neoinstitucionalismo. Lua Nova: Revista de Cultura e Política [online]. São Paulo, n. $58,2003$.

12 Idem.

13 GRANOVETTER, Mark. Le marché autrement. Paris: Desclée de Brouwer, 2000, p. 208.

14 GRANOVETTER, Mark. Economic action and social structure: the problem of embeddedness. American Journal of Sociology, v. 91, n. 3, p. 481-510. 15 Idem.
} 
sociais. Granovetter infere que as instituições são "cristalizadas", inertes e, uma vez constituídas, tendem a excluir outras possibilidades no futuro, mesmo se ocorrer uma mudança na estrutura social: é o fenômeno de trancamento $(\text { lock-in })^{16}$. Esta inércia é explicada pelos investimentos em tecnologias, equipamentos, lobbys, treinamento, cujo valor vai desestimular qualquer veleidade de mudança.

Devido à inércia, ou dependência de caminho, as instituições podem perdurar apesar de sua ineficiência. $\mathrm{O}$ acúmulo de capital, relações políticas e know-how podem perpetuar instituições.

David BAYLEY define as instituições policiais como "aquelas organizações destinadas ao controle social com autorização para utilizar a força, quando necessário"17. O que caracteriza a atividade policial, portanto, é a possibilidade do uso da força. Tal definição, porém, não marca a diferença entre as instituições policiais e as forças armadas.

A diferença principal, segundo o autor, recai na situação de emprego. Enquanto as forças armadas são empregadas no controle social em situações excepcionais e, no caso dos regimes democráticos, dentro de determinado limites, as polícias realizam essa tarefa cotidianamente ${ }^{18}$.

Jerome Skolnick destaca o caráter conflitivo da atividade de controle social por parte das instituições policiais num regime democrático, inferindo que

se as polícias pudessem manter a ordem sem se preocupar com os aspectos da legalidade, suas dificuldades diminuiriam consideravelmente. Entretanto, elas estão inevitavelmente preocupadas em interpretar a legalidade, uma vez que usam a lei como instrumento da ordem ${ }^{19}$.

\section{O PROCESSO DE TRANSIÇÃO DEMO- CRÁTICA E A “ORDEM" GARANTIDA PELO ENCLAVE MILITAR}

No Brasil esse processo de redemocratização revelou-se "lento e gradual", controlado pelo próprio

\footnotetext{
16 Idem.

17 Bayley, David. The police and political development in Europe. In: TILLY, Charles. The Formation of National States in Western Europe. Princeton: Princeton University Press, 1975, p. 328.

18 Idem.

19 SKOLNICK, Jerome. Justice without a trial. New York: Macmillian, 1994, p. 6.
}

regime ditatorial, "fazendo que o modelo de policiamento permanecesse intocado em suas características principais. Mesmo diante da intensa transformação da sociedade brasileira, duas polícias estaduais - uma civil, investigativa e judiciária, outra militar, ostensiva e fardada - permaneceriam como as principais organizações de segurança pública" ${ }^{20}$, revelando a tendência de militarização das políticas públicas de segurança, em especial na preservação da ordem pública.

Segue forte a militarização da sociedade e a policialização das políticas públicas, observável quando a polícia é chamada para resolver problemas sociais ou quando a retórica oficial repete ad nauseam: a polícia vai na frente e depois fazemos ocupação social. Discurso que não se sustenta uma vez que a polícia entra e a ocupação social fica sempre para depois, isto é, quando a polícia também não se vai ${ }^{21}$.

As investidas democráticas nas instituições policiais são salutares, porém, duramente criticadas quando perfazem apenas o mundo das ideias:

Os discursos sobre a implantação de policiamento comunitário, respeito aos direitos humanos ou mediação de conflitos, têm existência teórica nos cursos de formação, mas na prática, volto a dizer, funciona o que de fato aprendem e internalizam por meio da cultura da organização e o currículo oculto que produzem. Refiro-me ao famoso: esqueçam tudo o que vocês aprenderam [teoricamente]... $\mathrm{o}$ aprendizado real começa aqui [nas ruas] $]^{22}$.

Conforme esclarece Marcello Martinez Hipólito, o policial, já no período de formação, recebe o treinamento enclausurado numa sala de aula que pouco reproduz as práticas futuras. Assimila rapidamente os valores da instituição, transmitidos pelos colegas mais antigos, fragilizado pela situação de anomia com que depara. É muito difícil ensinar ao jovem policial hábitos opostos aos que the recomendam seus colegas antigos quando ele chega a um serviço ${ }^{23}$.

20 MEDEIROS, Mateus Afonso. A desmilitarização das polícias e a legislação ordinária. Revista de Informação Legislativa, Brasília, n. 165, jan./ mar., 2005, p. 239-40.

21 Idem.

22 MORAES, Pedro Rodolfo Bodê de. O Largo da (Des)Ordem [online]. Disponível em: <http://www.ninc.com.br/coluna-especial-detail.php?id_ coluna $=8>$. Acesso em: 27 jun. 2013 .

23 HIPÓLITO, Marcello Martinez. A Formação Policial no Brasil e seus Desafios. Revista Jurídica do Ministério Público Catarinense. Florianópolis, v. 3, p. 55-64, 2004. 
"A teoria na prática é outra". Essa é uma importante lição nas academias de polícia, nas ruas, na fala dos policiais calejados. É um alerta: para "tirar polícia", se manter na carreira, é preciso saber lidar com as "carteiradas" de dentro e de fora da polícia. $\mathrm{Na}$ "prática", cada policial tem que inventar, a cada nova circunstância, seu próprio equilíbrio entre a "convivência" e a "conivência" com os interesses e negócios que atravessam o fazer policial. Saber lidar com os momentos em que o que se aprendeu e deseja praticar da patrulha, da investigação, da inteligência, do atendimento emergencial, das atividades assistenciais ou das operações especiais pode ser posto em xeque por algum "acerto", antes, durante ou mesmo depois de uma ação policial. Esse é um aprendizado doloroso para os jovens policiais, que vão descobrindo a desencantada realidade do trabalho policial no Brasil: "a polícia tem vários patrões" ${ }^{\prime 2}$.

Nessa representação social constata-se a construção recíproca de preconceitos entre a sociedade e a polícia, dificultando o envolvimento verdadeiro dos órgãos de segurança pública nas questões sociais, o que contribui, também, para a sua ausência no espaço da cidadania. Bloqueia-se, portanto, o alcance da segurança pública no campo das políticas públicas, seja por meio do debate político, seja mediante a discussão de cunho teórico. Seus profissionais são distanciados da categoria social servidor público, cuja atribuição social consiste na viabilização de políticas públicas $^{25}$.

Quando trata sobre o tema "segurança pública", a Constituição está repleta de conceitos imprecisos: o de "ordem pública", por exemplo, que pode ser ajustado de acordo com as circunstâncias e conveniências liberais, para justificar um ou outro tipo de intervenção policial. Esse conceito é passível de incorporações autoritárias, como as realizadas pelas políticas de "lei e ordem" e de "tolerância zero"26.

24 MUNIZ, Jacqueline de Oliveira; PROENÇA JÚNIOR, Domício. Muita politicagem, pouca política sãos problemas da polícia [online]. Disponível em <http://www.scielo.br/pdf/ea/v21n61/ a11v2161.pdf>. Acesso em: 21 ago. 2013.

25 DIAS, Lúcia Lemos. Op. cit.

26 As políticas de segurança pública calcadas na teoria da "lei e ordem" e na técnica policial intitulada "tolerância zero" apregoam a receita de combater a violência cotidiana e a criminalidade comum com o aumento do poder punitivo em suas diversas formas, isto é, enrijecendo a criminalização primária, endurecendo as penas privativas de liberdade, enfim, com o cenário da hipercriminalização e do ultraencarceramento, e de outra monta, no aspecto da criminalização secundária, trabalham com a legitimação do "poder punitivo subterrâneo", das execuções sumárias e da violência policial, entre outras práticas.
Porém, a ordem também pode coabitar com o discurso democrático, concebida como instituto necessário em uma república, garantidora de princípios constitucionais e necessária ao desenvolvimento sustentável da sociedade. A interpretação equivocada de alguns doutrinadores e especialistas (até por conta da ambiguidade apresentada) induz, muitas vezes, à prática de políticas autoritárias ${ }^{27}$.

O papel das polícias na realização do controle social varia de Estado para Estado. Quanto mais central for esse papel, maior a possibilidade de conflito entre a lei e a ordem. Isso se deve ao fato de que o instrumento de atuação das polícias, e seu traço diferenciador, é o uso da força ${ }^{28}$ para a garantia da lei e da ordem.

O conceito de ordem pública está estatuído no art. $2^{\circ}, n^{\circ} 21$, do Decreto Federal $n^{\circ} 88.777 / 83$ (Regulamento para as Polícias Militares e Corpos de Bombeiros Militares):

(...) conjunto de regras formais, que emanaram do ordenamento jurídico da Nação, tendo por escopo regular as relações sociais de todos os níveis, do interesse público, estabelecendo um clima de convivência harmoniosa e pacífica, fiscalizado pelo poder de polícia, e constituindo uma situação ou condição que conduza ao bem comum.

Como sustenta Diogo Figueiredo Moreira Neto, o conceito legal é empolado, confuso e cheio de equívocos, pelos seguintes motivos: (1) não são regras, mas o resultado apreciável de sua observância, ou seja, uma situação que se quer manter ou à que se quer chegar, se for alterada e, permanecer este entendimento, ficariam de fora as referências à moral e aos costumes vigentes; (2) ainda se fosse a ordem pública reduzida a um conjunto de regras formais, não fica claro como este conjunto poderia regular as relações sociais de todos os níveis do interesse público; (3) ao fazer menção à fiscalização do poder de polícia, esquece-se dos demais meios de atuação (atos normativos, consentimento e sanção de polícia); (4) e, por último, quando expressa a finalidade

\footnotetext{
27 SOUZA NETO, Cláudio Pereira de. A segurança pública na Constituição Federal de 1988: conceituação constitucionalmente adequada, competências federativas e órgãos de execução das políticas [online]. Disponível em <http://www.oab.org.br/editora/revista/users/revista/120550597417 4218181901.pdf>. Acesso em: 02 jun. 2013.

28 COSTA, Arthur Trindade Maranhão. Estado, Polícia e Democracia. Tese (Doutorado), Universidade de Brasília, Programa de pós-graduação em Sociologia, 2001, cap. 1.
} 
de alcance do bem comum, abre margem a ações discricionárias, excessos e abusos dos agentes públicos em prol da supremacia do interesse público ${ }^{29}$.

O artigo XXIX, II, da Declaração Universal dos Direitos Humanos permite a restrição dos direitos fundamentais para assegurar a ordem pública, desde que reguladas pelo ordenamento jurídico:

No exercício destes direitos e no gozo destas liberdades ninguém está sujeito senão às limitações estabelecidas pela lei com vista exclusivamente a promover o reconhecimento e o respeito dos direitos e liberdades dos outros e a fim de satisfazer as justas exigências da moral, da ordem pública e do bem-estar numa sociedade democrática.

Numa democracia a preservação da ordem pública deve, portanto, respeitar o ordenamento jurídico, elementos que, de forma integrada e harmoniosa, devem garantir os interesses de uma nação livre e soberana. O poder de polícia, quando garantidor desta ordem pública, não deve se afastar dessa premissa ${ }^{30}$.

Pedro Rodolfo Bodê de Moraes expressa que a manutenção da ordem é uma questão de grande interesse para todo e qualquer cidadão. Processo este que está presente nas atividades públicas e privadas de todos: a organização de rotinas domésticas e o comportamento no trânsito são exemplos disto ${ }^{31}$.

Em stricto sensu a mesma manutenção da ordem pode ser vista como responsabilidade de agentes especializados, e, em qualquer lugar do mundo, é uma das funções da polícia. Num simplório exercício lógico, pode-se dizer que "ordem é ausência de desordem". Sinônimo de organização pode ser entendida como a ausência de conflito ou da ausência do que se possa entender como comportamentos inapropriados. O sentido do termo, porém, é muito mais profundo e encerra desde elementos individuais e referidos à construção de nossas identidades até elementos históricos ${ }^{32}$.

29 MOREIRA NETO, Diogo de Figueiredo. Direito administrativo da ordem pública. 2. ed. Rio de Janeiro: Forense, 1987, p. 138.

30 O conceito de poder de polícia se extrai do art. 78 do Código Tributário Nacional: considera-se poder de polícia atividade da administração pública que, limitando ou disciplinando o direito, interesse ou liberdade, regula a prática de ato ou a abstenção de fato, em razão de interesse público concernente à segurança, à higiene, à ordem, aos costumes, à disciplina da produção e do mercado, ao exercício de atividades econômicas dependentes de concessão ou autorização do Poder Público, à tranquilidade pública ou ao respeito à propriedade e aos direitos individuais ou coletivos.

31 MORAES, Pedro Rodolfo Bodê de. O Largo (...) Op. cit.

32 Idem.
Em relação à ação policial, há um desvirtuamento, como assevera Jean-Claude Monet, a ordem passa sempre à frente da lei ${ }^{33}$, com visíveis conotações políticas. No domínio da manutenção da ordem, a lei é equívoca: é precisa para determinar as infrações que os cidadãos podem cometer, mas flexível quanto aos meios empregados pela polícia e quanto às finalidades exatas que suas intervenções devem perseguir ${ }^{34}$.

As polícias são parte do aparato estatal de controle social e de proteção de determinados grupos, ideias e valores politicamente favorecidos. Porém, as mudanças econômicas e sociais não necessariamente fazem-se sentir em todo o aparelho estatal. É possível que parte do aparelho continue comportando-se a partir de valores e dentro de uma estrutura preexistente a tais mudanças ${ }^{35}$.

Algumas polícias latino-americanas, mesmo após as diversas mudanças políticas e sociais (transições democráticas), continuam apresentando comportamento violento e, muitas vezes, ilegal ${ }^{36}$. Em função destes problemas têm enfrentado o desafio de reformar suas forças policiais. Os esforços se concentraram na criação de mecanismos institucionais de responsabilização e controle, que estimulam as polícias a se submeter ao Estado de Direito e a respeitar as liberdades civis.

Entre as várias medidas que vêm sendo propostas e implantadas, podemos destacar: a ampliação das competências judiciárias, a criação de ouvidorias de polícia e as mudanças no treinamento policial a fim de incorporar os princípios de direitos humanos. Processos de reformas foram iniciados na Argentina, Brasil, Colômbia, El Salvador, Guatemala, Haiti, Honduras, México e Nicarágua. Apesar dos esforços, as reformas implantadas não lograram o êxito esperado ${ }^{37}$.

A manutenção desta ordem em muitos dos países latinos continua revelando-se truculenta e avessa ao discurso humanista:

El control punitivo del orden público estableció la pauta para el control social (en América Latina). Los gobiernos han eliminado los límites para

\footnotetext{
33 MONET, Jean-Claude. Polícias (...) Op. cit., p. 239.

34 Idem.

35 COSTA, Arthur Trindade Maranhão. Op. cit.

36 Idem.

37 COSTA, Arthur Trindade Maranhão. As reformas nas polícias e seus obstáculos: uma análise comparada das interações entre a sociedade civil, a sociedade política e as polícias. Civitas: Revista de Ciências sociais, v. 8 , p. $410,2008$.
} 
el poder coercitivo de la policía, las acciones de vigilantes paraestatales, y sobre la autoridad de las fuerzas de seguridad del estado. La tortura, el control del orden público militarizado, la fuerza letal, la privación de libertad sin juicio previo, y la negación de la ciudadanía para poblaciones inmigrantes criminalizadas han sido consideradas cada vez más necesarias, o se han convertido en las opciones políticas dominantes en democracias ya bien establecidas ${ }^{38}$.

Por conta de sua importância para a configuração de um Estado Democrático de Direito, os princípios fundamentais produzem eficácia irradiante sobre os demais preceitos que compõem a Constituição, inclusive sobre aqueles especificamente relacionados às forças de segurança pública ${ }^{39}$.

Considera-se ordem pública, objeto da segurança pública, a situação de convivência pacífica e harmoniosa da população, fundada em princípios de natureza ética dotados de eficácia. A ordem pública se exterioriza quando as instituições policiais, principalmente por meio de ações ostensivas e predominantemente preventivas, garantem os direitos dos cidadãos à vida harmônica e pacífica em sociedade ${ }^{40}$.

A tensão permanente entre esses dois blocos antagônicos - poder/autoridade/prerrogativas versus liberdade/garantias/sujeições - sedimenta um consenso no sentido de que é justamente este binômio que se mostra capaz de especializar este ramo de estudo peculiar que engloba o Direito Administrativo ${ }^{41}$.

Por essa razão, apenas as políticas de segurança pública alicerçadas em concepções democráticas, comprometidas com a observância efetiva desses princípios, são compatíveis com os Direitos Humanos, e o esforço de investimento primeiro deve ser realizado nos integrantes destas forças.

A agenda estatal democrática, conforme preleciona Juarez Freitas, deve buscar o direito fundamental à sustentabilidade multidimensional, incluso nesse conceito o direito à segurança pública de qualidade ${ }^{42}$.

\footnotetext{
38 SHEPTYCKI, James. Actuación policial frente a una protesta política, cuando la política se vuelve global. Cenipec, v. 25, p. 253, jan./dez., 2006

39 SOUZA NETO, Cláudio Pereira de. Op. cit.

40 LAZZARINI, Álvaro. Direito administrativo da ordem pública. 3. ed. Rio de Janeiro: Forense, 1998, p. 10.

41 HACHEM, Daniel Wunder. Princípio constitucional da supremacia do interesse público. Belo Horizonte: Fórum, 2011, p. 27-8.

42 FREITAS, Juarez. Sustentabilidade: Direito ao Futuro. Belo Horizonte: Fórum, 2011, p. 41.
}

Para o referido autor, o princípio da sustentabilidade é princípio constitucional implícito e deve regular o poder estatal de forma cogente. Segundo ele,

(...) trata-se do princípio constitucional que determina, independentemente de regulamentação legal, com eficácia direta e imediata, a responsabilidade do Estado e da sociedade pela concretização solidária do desenvolvimento material e imaterial, socialmente inclusivo, durável e equânime, ambientalmente limpo, inovador, ético e eficiente, no intuito de assegurar, preferencialmente de modo produtivo e precavido, no presente e no futuro, o direito ao bem-estar físico, psíquico e espiritual, em consonância homeostática com o bem de todos ${ }^{43}$.

A dimensão social da sustentabilidade se expressa com base nos direitos fundamentais sociais, com os correspondentes programas relacionados à saúde, à educação, e à segurança (serviços públicos por excelência), que precisam ser obrigatoriamente universalizados com eficiência e eficácia, sob pena de o modelo de gestão ser autofágico, ou seja, insustentável.

A Constituição, no seu art. 144, concebeu como finalidade das políticas de segurança a preservação da "incolumidade das pessoas e do patrimônio". Por outro lado, manteve parte importante da polícia militarizada. Embora subordinadas aos governadores dos estados, as polícias militares estaduais continuam previstas como "forças auxiliares e reservas do Exército" (art. 144, §5 $5^{\circ}$ CRFB).

$\mathrm{O}$ decreto-lei $\mathrm{n}^{\circ}$ 667/69 (que trata da "reorganização" das polícias militares e os Corpos de bombeiros militares dos estados, dos territórios e do Distrito Federal) esmiúça as competências das polícias militares:

Art. $3^{\circ}$ - Instituídas para a manutenção da ordem pública e segurança interna nos Estados, nos Territórios e no Distrito Federal, compete às Polícias Militares, no âmbito de suas respectivas jurisdições:

a) executar com exclusividade, ressalvadas as missões peculiares das Forças Armadas, o policiamento ostensivo, fardado, planejado pela autoridade competente, a fim de assegurar o cumprimento da lei, a manutenção da ordem pública e o exercício dos poderes constituídos;

b) atuar de maneira preventiva, como força de dissuasão, em locais ou áreas específicas, onde se presuma ser possível a perturbação da ordem;

43 Ibidem, p. 56. 
c) atuar de maneira repressiva, em caso de perturbação da ordem, precedendo o eventual emprego das Forças Armadas;

d) atender à convocação, inclusive mobilização, do Governo Federal em caso de guerra externa ou para prevenir ou reprimir grave perturbação da ordem ou ameaça de sua irrupção, subordinando-se à Força Terrestre para emprego em suas atribuições específicas de polícia militar e como participante da Defesa Interna e da Defesa Territorial;

e) além dos casos previstos na letra anterior, a Polícia Militar poderá ser convocada, em seu conjunto, a fim de assegurar à Corporação o nível necessário de adestramento e disciplina ou ainda para garantir o cumprimento das disposições deste Decreto-lei, na forma que dispuser o regulamento específico.

Instituições incumbidas da missão de policiamento ostensivo e da preservação da ordem pública, e que se organizam em conformidade com os princípios da hierarquia e da disciplina ${ }^{44}$, possuem sistema de patentes análogo ao que vigora nas Forças Armadas. O regime jurídico a que se submetem é semelhante ao das Forças Armadas, assim como a forma de organização e a estrutura hierárquica ${ }^{45}$.

Adequar estas instituições nascidas com o Estado Moderno, permeadas de resquícios arcaicos, com os princípios democráticos e de forma sustentável não é tarefa singela, mas também não se revela impossível.

\section{A NECESSIDADE DE MUDANÇA INSTITUCIONAL COMO ELEMENTO DE UMA JUSTIÇA TRANSICIONAL}

A organização em estudo, as polícias militares, sendo um aparelho repressivo do Estado e atravessada pelas contradições inerentes à realidade social onde está incrustada, não pode ser tratada como "um

\footnotetext{
44 Conceito extraído do Estatuto dos Militares (Lei 6880/80):

Art. 14. A hierarquia e a disciplina são a base institucional das Forças Armadas. A autoridade e a responsabilidade crescem com o grau hierárquico. $\$ 1^{\circ}$ A hierarquia militar é a ordenação da autoridade, em níveis diferentes, dentro da estrutura das Forças Armadas. A ordenação se faz por postos ou graduações; dentro de um mesmo posto ou graduação se faz pela antiguidade no posto ou na graduação. O respeito à hierarquia é consubstanciado no espírito de acatamento à sequência de autoridade.

$\$ 2^{\circ}$ Disciplina é a rigorosa observância e o acatamento integral das leis, regulamentos, normas e disposições que fundamentam o organismo militar e coordenam seu funcionamento regular e harmônico, traduzindo-se pelo perfeito cumprimento do dever por parte de todos e de cada um dos componentes desse organismo.

45 MUNIS, Jaqueline. A crise de identidade das polícias militares brasileiras: dilemas e paradoxos da formação educacional. Security and defense studies review, v. 1, inverno de 2001.
}

corpo de funcionários e de pessoal de estado unitário e cimentado em torno de uma vontade política unívoca, pelo contrário, lida-se com feudos, clãs, diferentes facções, em suma, com uma multidão de micropolíticas diversificadas que devem ter voz"46.

A ideologia institucional da polícia exige muito de seus profissionais, porém nem sempre exercita a comunicação com seus agentes. Somente sua inserção na discussão de suas rotinas laborais poderá mudar esse quadro de desvalorização profissional.

A desvalorização repercute nas percepções subjetivas dos policiais, conforme infere Susana Durão:

Algumas expressões orais ilustram as percepções subjetivas destes profissionais e sublinham uma situação de desvalorização do seu trabalho de rotina no contexto contemporâneo do policiamento. Por exemplo, em várias ocasiões, ironicamente, os agentes chamam uns aos outros de "Zé Patrulha" ou "Zé Polícia", derivado de "Zé Ninguém". Estes dizem frequentemente: "Nós aqui na polícia somos números, somos tratados como número". Cedo na carreira, os agentes manifestam o desejo de "fugir da patrulha", onde dizem que pouco podem fazer, nada podem inovar, onde defendem não nutrir reconhecimento profissional (...). Outras expressões recorrentes são: "Ser policial é difícil, somo pequenos", "Ninguém dá nada ao Zé Polícia"47.

E a dificuldade de implantação de uma política pública de segurança perpassa por esta evidência. Todo processo de implementação de uma política pública evidencia uma dinâmica de relacionamento entre os usuários e os burocratas implementadores, que, por meio da herança de valores, crenças e ideias transformam o modo como as políticas foram concebidas.

As decisões tomadas pelos burocratas "de nível de rua", as rotinas que eles estabelecem e as ferramentas que eles inventam para lidar com as incertezas e as pressões de seu trabalho efetivamente tornam-se as próprias políticas públicas que eles desenvolvem, podendo guiar o sucesso ou o insucesso de um modelo previamente estabelecido ${ }^{48}$.

\footnotetext{
46 POULANTZAS, Nikos. O Estado, o poder, o socialismo. Rio de Janeiro: Graal, 1980, p. 156.

47 DURÃO, Susana. Engenharias do policiamento em Portugal: no campo com as policias de segurança pública. In: LIMA, Roberto Kant; EILBAN, Lúcia; PIRES, Lenin (org.). Conflitos, direitos e moralidade em perspectiva comparada. v. 1. Rio de Janeiro: Garamond, 2010, p.157.
}

48 Idem, p. 12. 
O servidor público é o sujeito que medeia a relação entre o Estado e o cidadão cotidianamente, é a face que a Administração apresenta aos seus administrados. É por meio do servidor que a Administração se apresenta à vida do cidadão ${ }^{49}$.

O cerceamento de direitos sociais básicos aos policiais militares, como, por exemplo, o direito de greve e de sindicalização, ou até mesmo, em casos mais emblemáticos, o desrespeito à garantia ao direito de livre manifestação, parece causar impacto visível sobre as práticas de policiamento.

Reflexões referentes aos direitos dessa categoria de trabalhadores, que estão na linha de frente, "no nível de rua", na ponta do processo de construção de política públicas, podem ajudar na compreensão de por que alguns impasses na implementação das políticas públicas não são superados. Mais do que frutos de decisões tomadas em altos escalões estatais, as políticas públicas de segurança também são resultado do trabalho nas centrais 190 e nos encontros diários entre policiais e a população, resolvendo conflitos fundamentalmente sociais.

Esta visão converge, portanto, na importância de buscar compreender a relação nem sempre amistosa entre o universo das ações formais (regime jurídico, valores éticos singulares) e as ações informais que estão presentes nos processos de manifestações sociais, especialmente das praças, pela busca de concessão de direitos.

Muitos sustentam a conveniência de se extinguir as polícias militares sob o argumento de que se trata de instituição incompatível com a concepção democrática de segurança pública; a militarização da polícia levaria à conformação de um modelo bélico de política de segurança.

As dimensões da militarização das polícias se revelam pela: (1) organização: a polícia absorve modelos organizacionais, símbolos, valores e linguagem utilizados pelas forças armadas; (2) treinamento: a polícia adota armamento, treinamento, códigos e regulamentos disciplinares militares; (3) emprego: táticas e estratégias militares são incorporadas à atividade policial; (4) controle: a estratégia policial é definida pelas forças armadas ou, se as forças armadas não dirigem a ação policial, podem controlar al-

49 ROCHA, Cármen Lúcia Antunes. Princípios Constitucionais dos Servidores Públicos. São Paulo: Saraiva, 1999, p. 82. guns de seus aspectos, como a compra de armamento e a distribuição geográfica do policiamento; (5) inteligência: atividades de inteligência são controladas pelas forças armadas ou de algum modo influenciadas pelo processo decisório militar; (6) justiça: a polícia está inteira ou parcialmente sujeita à jurisdição de tribunais militares ${ }^{50}$.

$\mathrm{O}$ argumento da desmilitarização das polícias, formulado em abstrato, parece procedente. Em um estado democrático de direito, resta lógico ter organizações policiais de caráter civil. Assim sustenta Pedro Rodolfo Bodê de Moraes:

Se for possível afirmar que dentre as instituições mais resistentes à mudança e à integração à democracia estão as polícias estaduais, muito do seu arcaísmo segue garantido pelo art. 144 da Constituição Federal. (...) Antes de continuarmos vale lembrar que não existe instituição que não seja organizada com base na hierarquia e disciplina, mas há uma grande diferença entre aquelas organizações que são militarizadas e as organizações civis. Pelo menos etimologicamente falando polícias deveriam ser sempre civis é o que indica o prefixo polis, o mesmo de política, e que tem sua origem na cidade grega, donde, a propósito, retiramos as bases da democracia moderna. É claro que há muita diferença entre o uso da palavra naquela realidade histórica e o uso que se faz contemporaneamente, de qualquer maneira talvez haja uma relação com o fato de que nos dois casos esteja se tratando de procedimentos de manutenção da ordem ${ }^{51}$.

O autor afirma categoricamente, em recente texto (ainda no prelo), que essa militarização é prejudicial à implementação das políticas públicas de segurança:

A existência de uma polícia militar é uma contradição em termos, como lembra Zaverucha (1994), um oxímoro, uma vez que o termo polícia, como indicado a partir de seu prefixo polis, deveria ser uma instituição civil. Militares são feitos para a guerra, mas para todos os fins, há um enorme consenso de que o que está em jogo é uma guerra contra o crime. (...) a polícia militar constitui-se naquilo que Zaverucha (1994) chamou de "enclave autoritário" no interior de Estado democrático.

50 COSTA, Arthur; MEDEIROS, Mateus. A desmilitarização das polícias: policiais, soldados e democracia.Teoria e Sociedade, Belo Horizonte, v. 1, n. 11,p. 66-89, 2003.

51 MORAES, Pedro Rodolfo Bodê de. Em defesa... Op. cit. 
Tendo se configurado e assumido o papel que hora desempenha durante o último ciclo ditatorial, ainda que tenha feito algumas mudanças, continua em sua estrutura uma corporação preparada mais para combater as classes perigosas do que para servir e proteger. Esta instituição que, dispondo de uma organização interna arcaica, com um alto grau de letalidade em suas ações - a polícia brasileira é uma das polícias que mais mata no mundo - e problemas de conduta e corrupção, é a instituição responsável quando não pela aplicação direta da política pública por um papel central na implementação dela ${ }^{52}$.

Essa "estética militar" por vezes acaba permeando os conhecimentos técnicos necessários ao emprego eficaz de uma força policial, destinada ao preparo psicológico do combatente para destruir o "inimigo".

Bem se vê que tanto a atual Constituição Federal como as leis regentes da matéria carecem de firme decisão política de caráter tecnorreorganizacional, que não se pode deixar influir por interesses corporativos (neste caso sempre muito fortes). Não há razão (sensata razão), senão argumentos só aparentemente úteis, para a estratégia militar interferir no âmago da estratégia policial, a ponto de determinar a existência de uma "polícia" militar. Em regime democrático, sob o império do Estado de Direito, não há espaço para este desvio profissional, ainda tão sedimentado entre nós, agora já mais por incúria administrativa que por razões políticas ${ }^{53}$.

Esse conjunto de estímulos (solenidade, rito, formalismo) pode despertar e internalizar no homem valores ocultos, muito mais abrangentes do que a hierarquia e a disciplina, como evidencia Arthur Trindade Maranhão Costa:

Usualmente a atividade policial é descrita como uma guerra contra o crime. Mais recentemente esta guerra vem ganhando outras dimensões: guerra contra as drogas, guerra contra a delinquência juvenil e mesmo guerra contra a corrupção. A analogia entre polícia e Exército é inadequada. Diferentemente dos soldados num campo de batalha, os policiais não têm a clara definição de quais são os seus inimigos; afinal, são todos cidadãos, mesmo os que

52 MORAES, Pedro Rodolfo Bodê de; KULAITIS, Letícia Figueira Moutinho.Controle ... Op. cit.

53 AMARAL, Luiz Otávio de Oliveira. Direito e segurança pública, a juridicidade operacional da polícia:O manual do policial moderno. Brasília: Consulex, 2003, p. 48. infringem a lei. Tampouco esses policiais estão autorizados a usar o máximo de força para aniquilá-los. Essa analogia permite que as polícias elejam seus inimigos normalmente entre os segmentos política e economicamente desprivilegiados, além de também incentivar o uso da violência ${ }^{54}$.

Esta corrente doutrinária considera urgente acabar com a cultura militar da polícia, já que todos os chamados atributos militares que devem estar no policial não são exclusividade do militar: hierarquia/ denominação dos postos, disciplina, vigor físico, fardamento, mobilidade operacional e ordem unida ${ }^{55}$.

Utilizando-se da teoria democrática deliberativa, infere-se que as decisões políticas devem necessariamente buscar na discussão pública e no debate fundamentado a sua base de constituição. Jürgen Habermas, ao elaborar o conceito de democracia discursiva, ou deliberativa, se preocupa com o modo que os cidadãos fundamentam racionalmente as regras do jogo democrático. Defende a proposta de que as deliberações políticas devem ocorrer na esfera pública, com a observância de procedimentos, quais sejam: o debate entre os envolvidos, a ação argumentativa, a linguagem orientada para entendimento e a participação dos potencialmente atingidos ${ }^{56}$.

Necessário, nesta concepção, que se institucionalizem negociações e formas de argumentação com o apoio da comunicação, isto é, do diálogo e do consenso. Este procedimento democrático garante a ação dos indivíduos ou grupos, os quais devem reconhecer-se como livres e iguais para que possam se comunicar, argumentando contra ou a favor de uma ideia, visando à obtenção do consenso.

Para o autor "no uso da linguagem orientada pelo entendimento, ao qual o agir comunicativo está referido, os participantes unem-se em torno da pretensa validade de suas ações de fala, ou constatam dissensos, os quais eles, de comum acordo, levarão em conta no decorrer da ação"

A teoria do discurso "estabelece um nexo interno entre considerações pragmáticas, compromis-

\footnotetext{
54 COSTA, Arthur Trindade Maranhão. Entre a lei e a ordem: violência reforma nas polícias do Rio de Janeiro e Nova York. Rio de Janeiro: FGV, 2004, p. 55.

55 AMARAL, Luiz Otávio de Oliveira. Op. cit., p. 47.

56 HABERMAS, Jürgen. Direito e Democracia: entre facticidade e validade. Tradução de Flávio Beno Siebeneichler. Rio de Janeiro: Tempo Brasileiro, 1997, v. 2. p. 9

57 Ibidem, v. 1, p. 36
} 
sos, discursos de autoentendimento e discursos da justiça, fundamentando a suposição de que é possível se chegar a resultados racionais e equitativos" $"$.

A legitimação do processo democrático deriva, portanto, segundo a teoria, "dos procedimentos e dos pressupostos comunicativos da formação democrática da vontade e da opinião dos interessados que, por sua vez, funcionam como canais para a racionalização discursiva das decisões do governo e da administração pública" 59 .

Em que pese o fato de só o sistema político ter poder para agir enquanto subsistema especializado em tomar decisões vinculantes, as estruturas comunicativas reagem como sensores às pressões dos problemas que perpassam toda a sociedade ou grupos e estimulam opiniões influentes ${ }^{60}$.

Conforme deduz Joshua Cohen:

A democracia deliberativa está ligada ao ideal intuitivo de uma associação democrática, na qual a justificação dos termos e condições da associação procedem através dos argumentos públicos e do raciocínio entre cidadão iguais. Cidadãos que compartilham um compromisso para a solução dos problemas da escolha coletiva através do raciocínio público e consideram suas instituições fundamentais como legítimas na medida em que elas estabelecem a moldura para a deliberação pública livre ${ }^{61}$.

Os processos de comunicação, além de colaborar para a melhoria das condições dos interessados, podem auxiliar na consecução das missões de organizações/instituições e legitimar a autoridade de quem detém o poder de direção. A maneira como as pessoas se conscientizam de seu trabalho, de seus patrões e delas mesmas é a base da autoridade social ${ }^{62}$.

Richard Sennett infere que a legitimação da autoridade só pode ocorrer num ambiente de comunicação construtiva ${ }^{63}$. Ao citar James Cribbin, o dirigente cooperativo:

58 Ibidem, v. 2, p. 19.

59 FARIA, Cláudia Feres. Democracia deliberativa: Habermas, Cohen e Bohman. Lua Nova, n. 49, 2000, p. 49.

60 Idem.

61 COHEN, Joshua. Reflections on Habermas on Democracy. Ratio Juris, v. 12, n. 4, dez., 1999.

62 SENNETT, Richard. Autoridade. Tradução Vera Ribeiro. Rio de Janeiro: Record, 2001, p. 144.

63 Compreende-se por autoridade uma condição de poder, de controle e influência, definido numa imagem de força. In: SENNETT, Richard. Autoridade. Op. cit.
Não hesita em ser vigoroso quando as circunstâncias o exigem, mas não recorre habitualmente às ordens diretas. Preza mais a autodisciplina do que a disciplina imposta e mais as sugestões construtivas do que o conformismo submisso. Considerando que a autoridade se baseia mais na competência do que na posição, esse líder interage com seus seguidores num processo de influência recíproca. Como instrutor de equipes, percebe que seu objetivo é ajudar os empregados a satisfazerem algumas de suas necessidades, ao mesmo tempo que realizam as metas do grupo e da firma. A comunicação flui livremente, é construtiva e se orienta para as finalidades para as quais o grupo existe. Por fim, se possível, os conflitos são resolvidos através da síntese de diversas opiniões ${ }^{64}$.

$\mathrm{O}$ autor expressa que "o vínculo de autoridade constrói-se a partir de imagens de força e fraqueza; é a expressão emocional do poder" 65 . Revela o "ingrediente essencial da autoridade: alguém que tem a força e a usa para guiar os outros, disciplinando-os e modificando seu modo de agir, através da referência a um padrão superior" ${ }^{\prime \prime 6}$.

\section{CONCLUSÃO}

$\mathrm{Na}$ atualidade fica claro como "os poderes formalmente legítimos das instituições dominantes inspiram um forte sentimento de ilegitimidade entre os que estão submetidos a ela" ${ }^{97}$. As pessoas, porém, por mais que considerem algumas figuras de poder como ilegítimas, podem sentir-se atraídas e se submeterem a elas.

Faz-se exatamente o contrário do que se espera. Deprecia-se constantemente e explicitamente a pessoa que representa a autoridade ou fantasia-se que não haveria mais problemas sem tal figura, mas, ao mesmo tempo, não se revela nenhum movimento verdadeiro no sentido do rompimento dessa relação. O que aparece é um medo da força da autoridade, indo desde o medo ao mau uso dessa força pela autoridade, até o desaparecimento dela, causando uma perda grave de referências.

Em instituições "arcaicas", que se apresentam com uma pretensão de autoridade aparentemente inatacável, as expectativas cognitivas e normativas

\footnotetext{
64 SENNETT, Richard. Autoridade. Op. cit., p. 157.

65 Ibidem, p. 13.

66 Ibidem, p. 30.

67 Ibidem, p.42.
} 
solidificam-se, formando um complexo indiviso de convicções, que atingem os que agem no interior de seu mundo vital social ${ }^{68}$.

Restrições à comunicação, determinadas por cerimoniais, protegem contra questionamentos à validade autoritária, formando uma síndrome de validade, amparada pelo dualismo: entusiasmo e medo, veneração e pavor $^{69}$. Necessário, portanto, que a instituição "polícia militar" seja repensada para que busque sua legitimidade não apenas pelo texto constitucional que lhe garante a primazia da missão de "policiamento ostensivo e preservação da ordem pública", exercício mais visível do monopólio legítimo da força, mas pelo consenso democrático, escutando não só a comunidade, premissa do policiamento comunitário, mas também e primeiramente seus agentes, devendo necessariamente apagar as lembranças da ditadura e sua herança militar, seu "pai morto"70.

\section{REFERÊNCIAS}

ADORNO, Sérgio. O monopólio estatal da violência na sociedade brasileira contemporânea [online]. Disponível em: <http://www.nevusp.org/ downloads/down078.pdf > . Acesso em: 06 jun. 2013.

AMARAL, Luiz Otávio de Oliveira. Direito e segurança pública, a juridicidade operacional da polícia: o manual do policial moderno. Brasília: Consulex, 2003.

Bayley, David. The police and political development in Europe. In: TILLY, Charles. The Formation of National States in Western Europe. Princeton: Princeton University Press, 1975.

COHEN, Joshua. Reflections on Habermas on Democracy. Ratio Juris, v. 12, n. 4, dez. 1999.

COSTA, Arthur Trindade Maranhão. As reformas nas polícias e seus obstáculos: uma análise comparada das interações entre a sociedade civil, a sociedade política e as polícias. Civitas: Revista de Ciências sociais, v. 8, 2008, p. 410.

COSTA, Arthur Trindade Maranhão. Entre a lei e a ordem:

68 HABERMAS, Jürgen. Direito e Democracia: entre facticidade e validade. v. 1. Tradução Flávio Beno Siebeneichler. Rio de Janeiro: Tempo Brasileiro, 2003, p. 42.

69 Ibidem, p. 42-3.

70 Agora sem pai, tens que lidar com a lembrança de um pai. Muita vez, essa lembrança é mais poderosa que a presença viva de um pai, é uma voz interna a ordenar e arengar, dizendo sim e não - um código binário, sim não sim não sim não, a reger cada um de teus menores movimentos, mentais ou físicos. Em que momento te transformas em ti mesmo? Nunca por inteiro: és sempre ele, em parte. Essa posição privilegiada em teu ouvido interior é sua última 'prerrogativa', e nenhum pai jamais a desprezou. O pai morto, do contista Donald Barthelme. (In: SENNETT, Richard. Autoridade. Op. cit., p. 27). violência e reforma nas polícias do Rio de Janeiro e Nova York. Rio de Janeiro: Editora FGV, 2004.

COSTA, Arthur Trindade Maranhão. Estado, Polícia e Democracia. (Tese de Doutorado). Universidade de Brasília, Programa de pós-graduação em Sociologia, cap. 1, 2001.

COSTA, Arthur; MEDEIROS, Mateus. A desmilitarização das polícias: policiais, soldados e democracia. Teoria e Sociedade, Belo Horizonte, v. 1, n. 11, p. 66-89, 2003.

DIAS, Lúcia Lemos. A Política de Segurança Pública entre o monopólio legítimo da força e os direitos humanos: a experiência da Paraíba no pós 1988. (Tese de Doutorado). Universidade Federal de Pernambuco, Programa de pósgraduação em Serviço Social. João Pessoa, 2010.

DURÃO, Susana. Engenharias do policiamento em Portugal: no campo com os policiais de segurança pública. In: LIMA, Roberto Kant; EILBAN, Lúcia; PIRES, Lenin (org.). Conflitos, direitos e moralidade em perspectiva comparada. v. 1. Rio de Janeiro: Garamond, 2010.

FARIA, Cláudia Feres. Democracia deliberativa: Habermas, Cohen e Bohman. Lua Nova, n. 49, 2000.

FREITAS, Juarez. Sustentabilidade: Direito ao Futuro. Belo Horizonte: Fórum, 2011.

GRANOVETTER, Mark. Le marché autrement. Paris: Desclée de Brouwer, p. 208, 2000.

GRANOVETTER, Mark. Economic action and social structure: the problem of embeddedness. American Journal of Sociology, v. 91, n. 3 .

HABERMAS, Jürgen. Direito e Democracia: entre facticidade e validade. v. 2. Tradução Flávio Beno Siebeneichler. Rio de Janeiro: Tempo Brasileiro, 1997.

HABERMAS, Jürgen. Direito e Democracia: entre facticidade e validade. v. 1. Tradução Flávio Beno Siebeneichler. Rio de Janeiro: Tempo Brasileiro, 2003.

HACHEM, Daniel Wunder. Princípio constitucional da supremacia do interesse público. Belo Horizonte: Fórum, 2011.

HALL, Peter A.; TAYLOR, Rosemary C. R. As três versões do neoinstitucionalismo. Lua Nova: Revista de Cultura e Política [online]. São Paulo, n. 58, 2003.

HIPÓLITO, Marcello Martinez. A Formação Policial no Brasil e seus Desafios. Revista Jurídica do Ministério Público Catarinense, Florianópolis, v. 3, p. 55-64, 2004.

LAZZARINI, Álvaro. Direito administrativo da ordem pública. 3. ed. Rio de Janeiro: Forense, 1998.

MEDEIROS, Mateus Afonso. A desmilitarização das polícias e a legislação ordinária. Revista de Informação Legislativa, Brasília, a. 42, n. 165, jan./mar., 2005.

MORAES, Pedro Rodolfo Bodê de. O Largo da (Des) Ordem [online]. Disponível em: <http://www.ninc.com.br/ 
coluna-especial-detail.php?id_coluna $=8>$. Acesso em: 27 jun. 2013.

MORAES, Pedro Rodolfo Bodê de. Em defesa do Estado ou da sociedade [online]. Disponível em: $<$ http://www.ninc. com.br/coluna-especial-detail.php?id_coluna $=13>$. Acesso em: 27 ago. 2013.

MOREIRA NETO, Diogo de Figueiredo. Direito administrativo da ordem pública. 2. ed. Rio de Janeiro: Forense, 1987.

MUNIZ, Jacqueline de Oliveira; PROENÇA JÚNIOR, Domício. Muita politicagem, pouca política são os problemas da polícia [online]. Disponível em: $<$ http:// www.scielo.br/pdf/ea/v21n61/ a11v2161.pdf $>$. Acesso em: 21 ago. 2013.

MUNIS, Jaqueline. A crise de identidade das polícias militares brasileiras: dilemas e paradoxos da formação educacional. Security and defense studies review, v. 1, inverno de 2001.

PERES, Paulo Sérgio. Comportamento ou instituições? A evolução histórica do neoinstitucionalismo da ciência política. Revista Brasileira de Ciências Sociais. [online]. São Paulo, v. 23, n. 68, 2008.

PEDROSO, Regina Célia. Estado autoritário e ideologia policial. São Paulo: Fapesp, 2005.
POULANTZAS, Nikos. O Estado, o poder, o socialismo. Rio de Janeiro: Graal, 1980.

ROCHA, Cármen LúciaAntunes. Princípios Constitucionais dos Servidores Públicos. São Paulo: Saraiva, 1999.

SENNETT, Richard. Autoridade. Tradução Vera Ribeiro. Rio de Janeiro: Record, 2001.

SHEPTYCKI, James. Actuación policial frente a una protesta política, cuando la política se vuelve global. Cenipec, v. 25 , p. 253, jan./dez., 2006.

SOUZA, Robson Sávio Reis. Política de segurança: grandes desafios [online]. Disponível em: <http://www.cartacapital. com.br/sociedade/politica-de-seguranca-publica-grandesdesafios>. Acesso em: 02 jun. 2013.

SOUZA NETO, Cláudio Pereira de. A segurança pública na ConstituiçãoFederalde1988: conceituaçãoconstitucionalmente adequada, competências federativas e órgãos de execução das políticas [online]. Disponível em: <http://www.oab.org.br/ editora/revista/users/revista/1205505974174218181901.pdf $\$$. Acesso em: 02 jun. 2013.

SKOLNICK, Jerome. Justice without a trial. New York: Macmillian, 1994.

Recebido em dezembro de 2013. Aceito em março de 2014. 